\title{
LO PASADO...ARADO: IMPACTO DEL DESARROLLO AGRÍCOLA MODERNO SOBRE EL PATRIMONIO ARQUEOLÓGICO PREHISPÁNICO DEL ÁREA PEDEMONTANA MERIDIONAL DE LA PROVINCIA DE TUCUMÁN (ARGENTINA)
}

\author{
THE PAST...PLOWED: IMPACT OF AGRICULTURE OVER THE \\ ARCHAEOLOGICAL HERITAGE IN THE SOUTHERN PIEDMONT AREA \\ OF TUCUMAN PROVINCE (ARGENTINA).
}

\author{
Gabriel Miguez \\ Instituto de Arqueología y Museo (Universidad Nacional de Tucumán). E-mail: gabrielmiguez7@hotmail.com
}

Presentado el: 17/06/2012 - Aceptado 15/08/2012

\section{Resumen}

En este trabajo se indaga acerca del grado de impacto que el intempestivo avance de la frontera agrícola ha tenido sobre el patrimonio arqueológico de las tierras bajas de la provincia de Tucumán, con el énfasis puesto en la porción meridional del área pedemontana. Se aborda el tema integrando los datos obtenidos en recientes prospecciones arqueológicas con el análisis bibliográfico de tópicos vinculados con el desarrollo de la agricultura moderna. A partir de ello se describen los principales mecanismos de alteración producidos por las actividades agrícolas sobre los restos arqueológicos y la incidencia de ciertos factores ambientales en dicho proceso destructivo. Se analiza también la magnitud de este impacto en perspectiva histórica y se reflexiona acerca de la difícil situación existente entre el progreso agrícola y la preservación de los sitios arqueológicos en la actualidad. Se concluye que las actividades agrícolas son la principal causa de alteración del patrimonio arqueológico en las tierras bajas tucumanas, afectándolo de múltiples maneras. La magnitud de este impacto ha ido en aumento desde hace más de un siglo, hecho que plantea la implementación de medidas urgentes para mitigar esta situación, algunas de las cuales se proponen aquí.

Palabras claves: Patrimonio Arqueológico, Impacto Antrópico, Desarrollo Agrícola, Piedemonte de Tucumán.

\footnotetext{
Abstract

This paper investigates the degree of impact of the untimely advancing agriculture frontier has had on the archaeological heritage in lowlands of the province of Tucuman, with the emphasis on the southern portion of the piedmont area. It aproach the issue by integrating data from recent surveys the literature review of topics related to the development of modern agriculture. Starting
} 
from this it describes the main mechanisms of alteration produced by agricultural activities on the archaeological remains and the impact of environmental factors in this destructive process. It also analyzes the magnitude of this impact in historical perspective and reflect on the difficult situation between agricultural progress and the preservation of archaeological sites today. We conclude that agricultural activities are the main cause of disturbance of archaeological heritage in the lowlands Tucuman, affecting it in multiple ways. The magnitude of this impact has been increasing for over a century, a fact that raises the implementation of urgent measures to mitigate this situation, some of which are proposed here.

Keywords: Archaeological Heritage, Human Impact, Agricultural Development, Tucuman Piedmont.

\section{Introducción}

En general la sociedad tucumana desconoce la relevancia del patrimonio arqueológico prehispánico del área de piedemonte y llanura de su provincia, por lo que no lo reconoce como parte de su identidad histórica. Una de las causas de dicha realidad ha sido la escasa atención que esta área ha recibido por parte de la comunidad científica arqueológica, tanto en lo que atañe a las tareas de investigación como a las actividades de difusión y transferencia a la comunidad.

Los escasos estudios previos consistieron en breves descripciones de algunos sitios arqueológicos a partir de trabajos de campo de carácter prospectivo (García Azcárate y Korstanje 1995; Korstanje 1992; Manasse 1997; Scattolin y Korstanje 1994; Tartusi y Núñez Regueiro 2003; entre otros). Estos trabajos han aportado los primeros datos sobre las ocupaciones prehispánicas situadas en ambientes selváticos del sur tucumano. Sin embargo la discontinuidad de las investigaciones, la falta de estudios regionales, cronologías y registros contextuales detallados no han permitido profundizar en el conocimiento de las poblaciones prehispánicas.

Para comenzar a revertir esta situación, desde hace algunos años se vienen llevando a cabo investigaciones arqueológicas sistemáticas regionales en la porción meridional del área pedemontana de la provincia de Tucumán, enfocadas en el estudio de los paisajes sociales (espacios habitados, construidos, experimentados y semantizados) producidos por las poblaciones prehispánicas durante el desarrollo de sus ocupaciones. En el marco de estos estudios se han efectuado intervenciones de campo con el objeto de explorar, en primer lugar, la variabilidad de las ocupaciones prehispánicas y la dinámica de poblamiento a nivel regional. Luego, tomando determinados sitios como casos de estudio, se están abordando las espacialidades -y temporalidades- de los paisajes sociales a una escala que abarca el sitio y su entorno inmediato (Miguez 2008, 2011).

En el contexto de la primera etapa de investigación, se han efectuado prospecciones en las que se registraron varios sitios arqueológicos ${ }^{1}$ (Figura 1), así como también los factores que inciden en su estado de conservación. Se pudo observar que casi la totalidad de los sitios se encuentran afectados por diversas actividades humanas, principalmente por acciones vinculadas a los distintos sistemas de cultivos atuales (Miguez 2007). La realidad percibida invita a reflexionar acerca de la magnitud de la gravedad de esta situación en el presente, sus raíces en el pasado y sus consecuencias a futuro. 


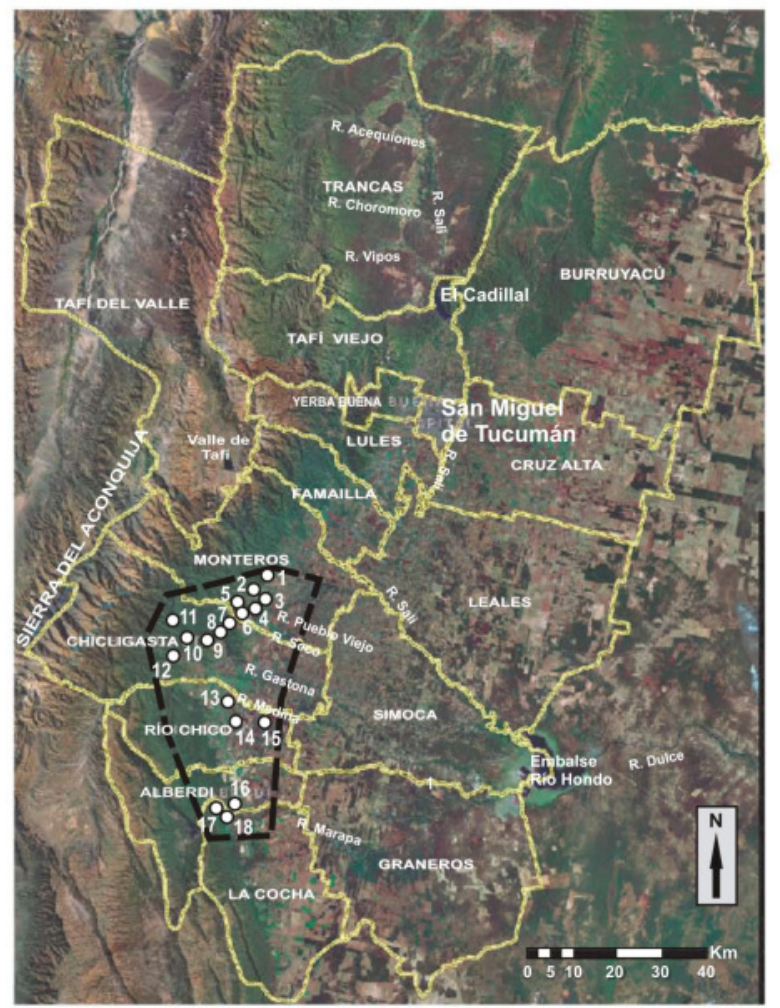

Figura 1. Ubicación del área de estudio y los sitios prospectados. En orden de norte a sur: 1-Rocha; 2-Cáceres 1; 3-Cáceres 2; 4-La Florida; 5-Moyaloma; 6-Moyaseco; 7-Cochamolles 1; 8-Cochamolles 2; 9-La Escondida; 10-La Loma; 11-Santa Rosa; 12-Alpachiri 1; 13-El Cebilar; 14-Loma Grande; 15-Aguila 2; 16-Loma de Marapa; 17-Yánimas 2; 18-Yánimas 1.

En tal sentido se considera importante no sólo investigar las poblaciones prehispánicas y los procesos sociales que generaron este patrimonio arqueológico -con el objeto de generar conocimiento y transferirlo a la comunidad-, sino también explorar y poner en debate la situación en que se encuentra dicho patrimonio por dos razones fundamentales: a- mostrar las principales actividades humanas que lo afectan y cómo estas se conjugan con los factores naturales en procesos de alteración de alto impacto; b- generar conciencia sobre la urgente necesidad de su protección a través de correctas políticas de conservación.

A pesar de que existen varios factores que actualmente alteran el patrimonio arqueológico en el área de estudio (naturales y culturales), en este trabajo abordamos específicamente los procesos de formación post-depositacionales que produce el desarrollo agrícola sobre los recursos arqueológicos a distintas escalas: restos, sitios y paisajes. En esta línea se examinan diferentes matices en la relación entre la explotación agrícola y el patrimonio arqueológico con el objeto de contestar preguntas tales como: ¿cuáles son los principales mecanismos a través de los cuales las actividades agrícolas alteran el patrimonio arqueológico y cuáles son las evidencias observables de estos procesos?, ¿qué sucede cuando las consecuencias de estas actividades se conjugan con otros factores naturales?, ¿qué procesos erosivos que se generan a partir del desarrollo de cada tipo de cultivo en relación a las unidades geomorfológicas donde se sitúan los sitios? 
Se indaga también la profundidad histórica que tiene el impacto agrícola en la región para comprender la incidencia que pudo haber tenido la expansión de la frontera agraria ha tenido sobre los paisajes arqueológicos a lo largo del tiempo. Se discutenlos efectos del desarrollo de la agricultura empresarial sobre dicho patrimonio, en el contexto provincial y también nacional. Finalmente se proponen algunas recomendaciones que podrían mejorar la conflictiva relación entre la agricultura moderna y la Arqueología, con el objeto de atenuar el impacto de la primera sobre los restos arqueológicos.

\section{Contexto ambiental del área de estudio}

El área pedemontana meridional de Tucumán constituye el espacio físico de transición entre las Sierras Pampeanas del SO provincial y la llanura oriental tucumano-santiagueña. El sector en estudio se encuentra aproximadamente entre los meridianos $65^{\circ} 30^{\prime}$ y $65^{\circ} 50^{\prime}$ L.O. y los paralelos $27^{\circ} 10^{\prime}$ y $27^{\circ} 40$ L.S., abarcando una superficie de $1800000 \mathrm{~km}^{2}$ (Figura 1). Geográficamente se extiende desde el río Los Sosa en el extremo septentrional, hasta el sector pedemontano ubicado al sur del río Marapa como límite meridional; mientras que de este a oeste se halla comprendida entre la Ruta Nacional 38 ( $350 \mathrm{~m} \mathrm{snm}$ de altura promedio) y los primeros faldeos de la Sierra del Aconquija y serranías menores hasta una altura de 1000-1100 m snm.

La mayor parte del área estudiada presenta un relieve irregular inclinado hacia el este, en el que abundan los sedimentos terciarios y cuaternarios. Las lomadas, los terrenos ondulados y los numerosos cursos fluviales que forman parte de la cuenca Salí-Dulce, tipifican su paisaje natural. El clima es de tipo monzónico-caliente, con lluvias estivales regionales e invernales locales, con veranos cálidos e inviernos secos. Las precipitaciones anuales, concentradas mayormente entre los meses de noviembre a marzo, rondan entre los 900 a $1000 \mathrm{~mm}$ (Sesma et al. 1998).

La vegetación predominante en el área considerada corresponde al estrato de Selva Pedemontana (400 a 700 m s.n.m.) de la Provincia Fitogeográfica de las Yungas. En esta selva caliente y de marcada estacionalidad hídrica, reinan especies arbóreas de gran porte y altura tales como el cebil (Anadenanthera colubrina), la tipa (Tipuana tipu), el pacará (Enterolobium contortisiliqum), el tarco (Jacaranda mimosifolia), entre otros (Brown et al. 2001). Hacia el oeste, a partir de los 700-800 m snm, esta formación selvática es reemplazada gradualmente por la Selva Montana de Yungas; mientras que hacia el oriente, entre los 300-400 m snm, se forman ecotonos con el bosque chaqueño occidental.

Las óptimas condiciones climáticas y edáficas del área han propiciado la progresiva conversión de sus selvas y bosques nativos en espacios agrícolas generando una fuerte presión en sus ecosistemas, principalmente sobre la Selva Pedemontana que actualmente se halla al borde de la extinción En general, los escasos relictos que quedan de este ecosistema mayormente corresponden a parches aislados de bosque secundario desarrollas en lugares donde anteriormente se practicaba la agricultura o la ganadería (Brown y Malizia 2004). Una de las áreas más afectadas por este proceso es la que se ubica al oriente de las Sierras del Aconquija, precisamente donde se centra este trabajo

(Figura 2), siendo los cultivos predominantes: la caña de azúcar, el citrus, el tabaco, la papa-semilla, las hortalizas, los granos tales como maíz, soja, etc. (Gasparri y Menéndez 2004, en Brown y Malizia 2004), y ahora también el arándano. 
Es importante resaltar que el desmonte de grandes superficies y su conversión en áreas de cultivo, sumado a la naturaleza del sustrato pedemontano (sedimentos loésicos y detríti$\cos$ ), las fuertes pendientes y la intensidad de las lluvias estivales, son factores concurrentes que intensifican los procesos de erosión hídrica y la pérdida de sedimentos, suelos (Sayago et al. 1998) y restos arqueológicos.

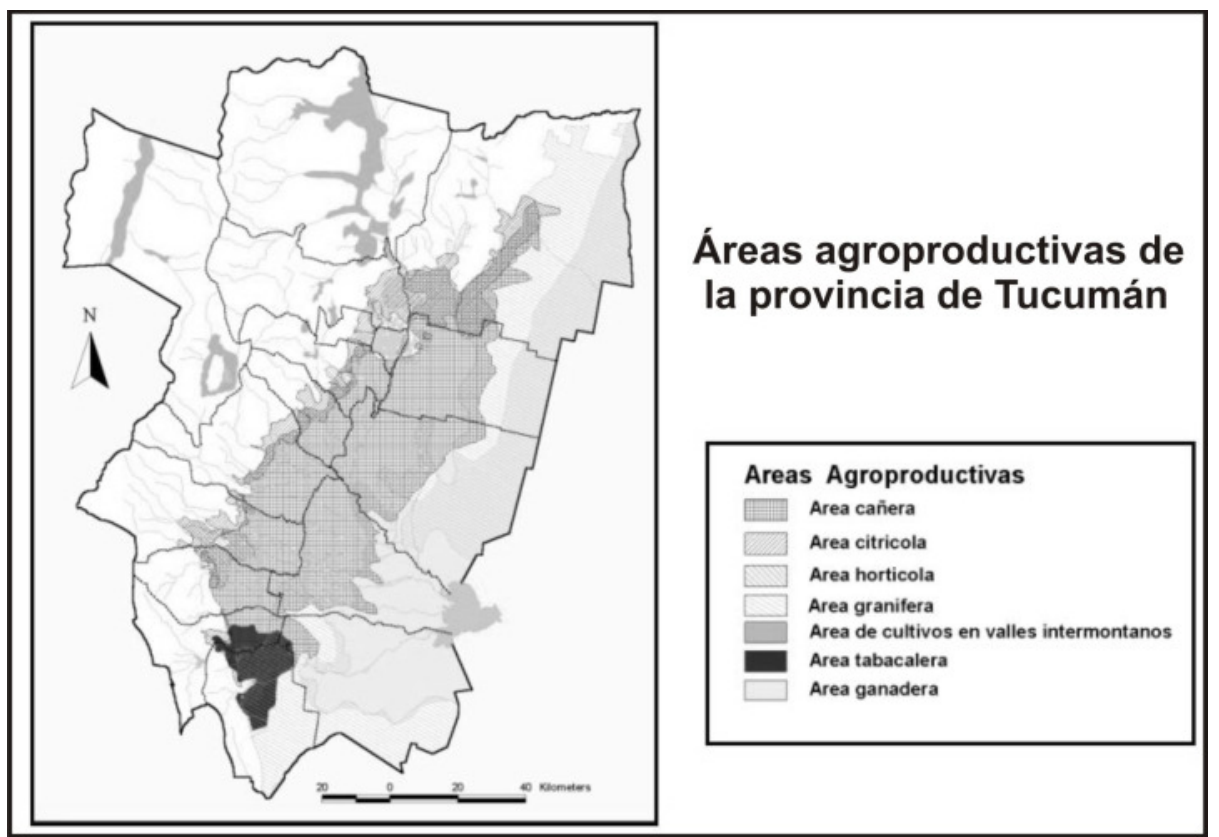

Figura 2. Tipos de cultivos y su distribución en las tierras bajas de Tucumán (modificado de Mancilla et al. 2010).

\section{Patrimonio arqueológico, paisaje y procesos de formación post-depositacionales}

Se considera al Patrimonio Cultural como una construcción social colectiva cargada de un fuerte carácter simbólico e identitario (Prats 1997), aplicada a los bienes culturales (materiales e inmateriales) que forman parte del desarrollo histórico de una entidad social. En un sentido amplio, el patrimonio cultural abarca un conjunto de clases o tipos de patrimonios entre los que se halla el Patrimonio Arqueológico, que está constituido por todos los restos materiales -y sus contextos de depositación- que dan cuenta de la existencia y forma de vida de grupos humanos en el pasado, y que formaron parte de procesos sociales en los cuales dichos restos cobran sentido (Endere 2000). Su importancia radica en que a través de su vinculación con un pasado concreto, construido y revalorizado de acuerdo a ciertos cánones sociales, un grupo humano fortalece su propia identidad, generando profundos lazos con su territorio, sus antepasados y con la herencia patrimonial tangible e intangible que legaron.

Sin embargo, para que cualquier entidad social se identifique con el patrimonio arqueológico que es herencia de su pasado no sólo debe tener pleno conocimiento de los bienes que lo constituyen y de los procesos sociales que integraron, sino también del estado en que se encuentra y los factores que lo afectan, para saber cómo protegerlo a través de correctas políticas de manejo de los recursos patrimoniales (Molinari et al. 2000). 
¿De qué forma es posible conocer el estado en que se encuentra el patrimonio arqueológico en el piedemonte tucumano? La UNESCO (1972) establece que el Patrimonio Cultural junto con el Natural conforman el Patrimonio Universal de la humanidad, y que ambos deben ser integrados en las políticas estatales de planificación general, desarrollando programas de protección y puesta en valor. En consonancia con ello, actualmente se acepta que el único acercamiento fructífero a cualquier clase de patrimonio cultural es aquél que lo reconozca como parte integrante e inseparable de un constructo humano y natural. Por ello, es necesaria una visión que integre diferentes puntos de vista, realizando una lectura ambiental, social, política, económica e ideológica del entorno, trascendiendo el sitio arqueológico y abarcando el contexto que lo explica: el paisaje circundante (Ballesteros Arias et al. 2005).

De hecho las instituciones internacionales, nacionales y los marcos legales referidos al patrimonio cultural y arqueológico están incorporando al paisaje como herramienta conceptual fundamental en las políticas de protección y conservación del mismo (Endere 2000), lo que genera la necesidad de poner en práctica estudios y evaluaciones del registro arqueológico que incluyan dichas escalas espaciales (Amado Reino et al. 2002; Criado Boado 1996).

Se entiende por paisaje arqueológico como el resultado de la incidencia acumulada en el espacio-tiempo tanto los desarrollos sociales pasados sobre el entorno natural y de los procesos de formación de sitio. En cada paisaje los restos materiales se distribuyen de manera singular en el espacio, resultando de ello una serie de rasgos formales que atestiguan la producción y reproducción de prácticas sociales (económicas, sociales e ideológicas), integradas y articuladas de acuerdo con determinados criterios racionales de los agentes, grupos o poblaciones humanas del pasado (Criado Boado 1993, 1996, 1999; Hernando 2004), pero también las alteraciones producidas por los agentes naturales y humanos. Pero dichos rasgos también manifiestan las alteraciones producidas por los fenómenos naturales y por las acciones de las personas durante o en momentos posteriores a la ocupación pretérita de un espacio dado.

Durante la constitución de un paisaje social "en vida”, y aún más luego de su abandono, los agentes naturales componentes de su matriz medioambiental están siempre presentes, actuando e interactuando con los agentes culturales en su proceso de formación. De esta forma, el paisaje arqueológico (producto actual del paisaje social), es en si mismo un todo complejo en el que confluyen y se integran procesos de diversa naturaleza través del tiempo, razón por la cual tendría que ser abordado a través enfoques interdisciplinarios que complementen y ayuden a la Arqueología del Paisaje no solo en la investigación de este patrimonio sino también en la evaluación del estado de sus bienes (Criado Boado 1996, 1999).

Se incorpora la noción de paisaje para trabajar tanto con una escala de análisis local, incluyendo al sitio arqueológico y su entorno socio-ambiental inmediato, como también desde una perspectiva regional, más abarcativa y generalizadora. De forma más concreta, se concibe al sitio como distribución más o menos discreta de restos arqueológicos registrados en superficie o debajo de ella, presentando continuidad o discontinuidad de dichos materiales a lo largo de toda su extensión ${ }^{2}$. En un nivel todavía más específico, los restos tales como artefactos y ecofactos (o partes del ellos) se distribuyen en un área de diferentes formas, constituyendo a los sitios o paisajes arqueológicos. 
Uno de los aspectos más relevantes del trabajo arqueológico es registrar, analizar, evaluar y difundir a la comunidad científica y a la sociedad en general, las características de los procesos que afectan el patrimonio arqueológico en cada región. ¿Por qué? Porque ello permitirá debatir con bases científicas sobre la gravedad que reviste cada situación en particular, establecer las responsabilidades de las entidades intervinientes y plantear las correctas medidas tendientes a proteger y preservar los sitios o paisajes afectados. Es por ello, que creemos de fundamental importancia la realización de este trabajo.

La exploración acerca del estado en que se encuentran los bienes patrimoniales arqueológicos registrados en el área de estudio se realizará a partir de la descripción y análisis de determinados procesos de formación de sitio culturales postdepositacionales, denominados procesos de disturbación, que son los que alteran el registro arqueológico a nivel superficial o subsuperficial (Schiffer 1987). Específicamente, el eje central del artículo girará en torno a las transformaciones que generan las prácticas agrícolas, identificando y registrando las trazas o huellas (indicadores directos) que acciones vinculadas con los desmontes, el arado, los aplanamientos superficiales, etc., dejan en el registro arqueológico a diferentes escalas: restos, sitios y paisajes.

Como complemento de las tareas arqueológicas de campo, se integrarán a este análisis algunos conceptos y técnicas proporcionadas por la geoarqueología, como la fotointerpretación geomorfológica de fotografías aéreas y la identificación de procesos erosivos en el campo, que son indicadores indirectos del impacto antrópico agrícola en los sitios considerados.

El reconocimiento de las unidades geomorfológicas - entendidas como formas características de relieve y definidas por una génesis y evolución morfodinámica particular (Sayago 1982) -, donde se ubican los sitios arqueológicos, nos permitió comprender mejor la dinámica de interacción entre las condiciones naturales, las acciones antrópicas y los restos arqueológicos.

\section{Metodología}

El registro de los restos, sitios y paisajes arqueológicos, la caracterización formal-espacial y ambiental de los mismos, y la identificación de procesos post-depositacionales, implicó la realización de varias estrategias prospectivas que incluyeron: a- encuestas abiertas a lugareños; b- sectorización y aplicación de diferentes tácticas pedestres de prospección: la asistemática o tradicional, el barrido mediante sistemas de transectas, la cobertura total, etc. (Gallardo y Cornejo 1985; García Sanjuán 2005); c- registro y recolección indiscriminada de restos arqueológicos superficiales; d- relevamiento de recursos (geológicos y biológicos) disponibles en el paisaje; e- registro de procesos de alteración naturales; f- relevamiento de indicadores de procesos de alteración antrópica.

La ubicación precisa de sitios y restos arqueológicos significativamente visibles en el paisaje se efectuó con GPS. Toda la información obtenida fue volcada en fichas de prospección estandarizadas. En cada intervención se efectuó el relevamiento fotográfico correspondiente de las características culturales y ambientales de los sitios y de los procesos de alteración registrados. 
El registro análisis de los efectos directos o indirectos que produjeron las actividades agrícolas sobre los recursos arqueológicos, sirvieron para efectuar una evaluación del estado de conservación de cada sitio arqueológico y su entorno inmediato, para lo cual se tuvieron en cuenta las siguientes variables: a) unidad geomorfológica; b) procesos de alteración natural; c) cobertura vegetal natural/exótica; d) uso del suelo; e) pendiente; f) alteraciones en los depósitos y materiales arqueológicos.

Las unidades geomorfológicas donde se sitúan los sitios registrados fueron determinadas mediante la fotointerpretación de fotografías áreas a escala 1:50000 (año 1976). Las demás variables fueron registradas en el terreno. El mapa que se muestra como resultado de la fotointerpretación (Figura 3) representa aproximadamente un 80 \% del área de estudio (sector centro-norte), ya que no han podido acopiarse varias de las fotografías necesarias para completar un mapa geoarqueológico unificado para toda el área de estudio ${ }^{3}$.

Por último, para caracterizar los principales mecanismos de alteración producidos por las actividades agrícolas sobre este patrimonio, y también para analizar la incidencia de la expansión de la frontera agrícola en la destrucción de los paisajes arqueológicos en perspectiva histórica, se integra la información arqueológica con la procedente del análisis de la bibliografía referente a los cultivos y actividades agrícolas relevadas.

\section{Resultados}

En general los sitios arqueológicos prehispánicos registrados durante las prospecciones se caracterizan por presentar restos cerámicos, materiales líticos tallados y artefactos de molienda, en algunos casos distribuidos manera regular en el terreno, pero en otros se manifiestan de forma discontinua, observándose diferentes concentraciones de materiales que pueden deberse a varios factores (visibilidad, dinámica ambiental, actividades humanas pasadas y actuales, etc.). En unos pocos casos, tales como en Yánimas 1, Santa Rosa y Cochamolles 2 se han relevado estructuras en forma de montículos o alienamientos de piedra. Se ubican sobre variadas geoformas tales como glacis, planos interfluviales, niveles aterrazados, y diferentes niveles de paleoconos -entre otras- que conforman la compleja geomorfología que posee el área considerada (ver Figura 3). La mayoría presenta evidencias de alteraciones por acciones humanas que se desarrollan en la actualidad y/o que tuvieron lugar en el pasado histórico reciente. Además en varios de ellos se observaron importantes procesos naturales de alteración, principalmente por erosión hídrica, que fueron originados o intensificados por el impacto antrópico (Tabla 1)

En el espacio que comprende cada sitio arqueológico y sus alrededores, se observaron diferentes sectores alterados por la explotación agrícola tales como espacios arados/ cultivados, caminos, represas, depósitos/galpones, viviendas, etc. De todos ellos, los arados/cultivados son los espacios más extensos y en donde se despliegan las acciones más destructivas sobre el registro arqueológico ya que, además del arado (usado en diferentes direcciones y profundidades), también se deben considerar los efectos que producen el desmonte, el tránsito de vehículos (tractores, palas mecánicas, camiones, camionetas) y el uso de agroquímicos.

En los sectores cultivados de los sitios relevados se observaron distintas especies cultivadas tales como caña de azúcar (Saccharum sp.), citrus (Citrus limon), arándano (Vaccinium 
sp.), papa (Solanum tuberosum), soja (Glycine max), entre otras, siendo las dos primeras las que tienen mayor presencia en el área. Cada sistema de cultivo comprende un conjunto particular de actividades agrícolas que afectan de manera dispar los sitios arqueológicos

Los efectos directos e indirectos que producen las actividades agrícolas sobre los recursos arqueológicos pedemontanos están vinculados principalmente a un modo determinado de hacer agricultura: "la empresarial o moderna", que es la manera más recurrentemente practicada por empresas agrícolas o por particulares en sus terrenos (ver Tabla 1).

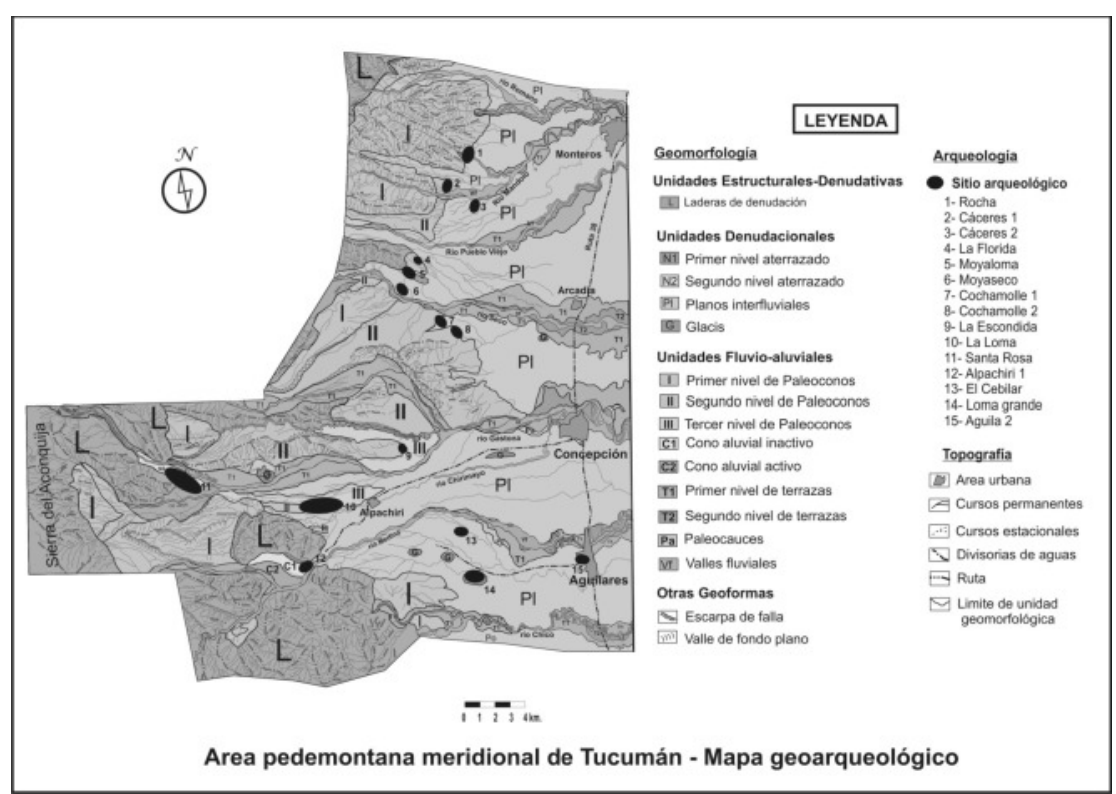

Figura 3. Mapa geoarqueológico que relaciona las unidades geomorfológicas con los sitios registrados (tomado de Miguez y Collantes 2012). Los sitios se hallan descriptos en la Tabla 1, con excepción de Loma de Marapa, Yánimas 1 y Yánimas 2 (ver nota al final).

\section{Alteraciones directas producidas por los sistemas de cultivos sobre el patrimonio arqueo- lógico pedemontano.}

Las actividades agrícolas transformadoras del registro arqueológico se inician con el desmonte, vale decir, la eliminación de la cubierta vegetal de una superficie destinada para el cultivo. Este se efectúa regularmente removiendo los árboles de raíz con topadora, y eliminando toda la vegetación remanente (arbustos, hierbas, etc.) mediante el uso del fuego. Estas actividades alteran los depósitos arqueológicos a nivel contextual, fundamentalmente cuando se usa la topadora para voltear árboles de gran tamaño ya que, al caer, sus sistemas radiculares extraen del suelo gran cantidad de sedimento y restos arqueológicos, generándose grandes oquedades de $50 \mathrm{~cm}$ o más de profundidad, que luego son niveladas con pala mecánica.

Luego del desmonte, el grado de impacto que generan las actividades agrícolas sobre los sitios arqueológicos depende fundamentalmente del tipo de cultivo y las unidades geomorfológicas donde se desarrollan, así como de otros factores tales como las precipitaciones y 


\begin{tabular}{|c|c|c|c|c|c|c|c|c|c|c|}
\hline & 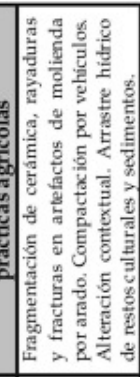 & 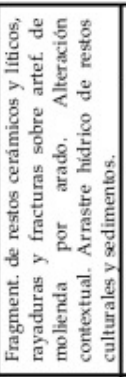 & 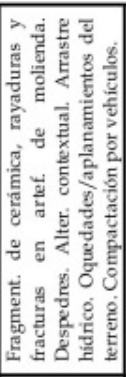 & & 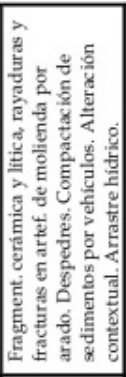 & 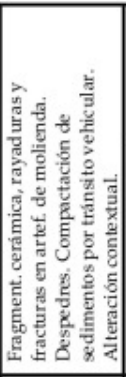 & 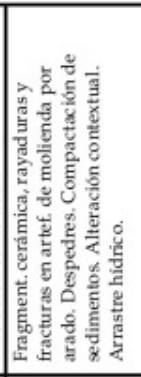 & 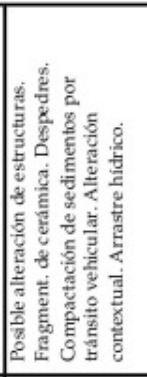 & 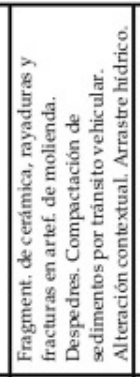 & 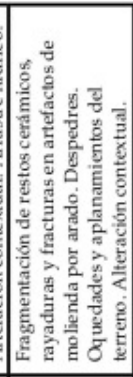 \\
\hline & & 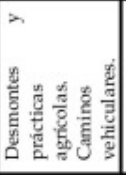 & $\frac{8}{\pi}$ & 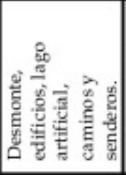 & 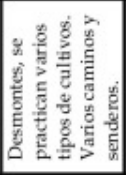 & 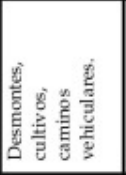 & 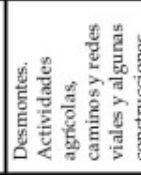 & 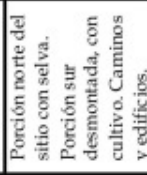 & 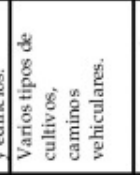 & 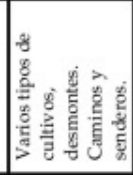 \\
\hline & 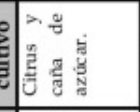 & है & 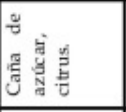 & 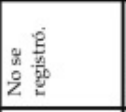 & 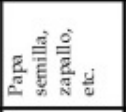 & 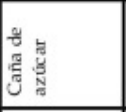 & E & E & 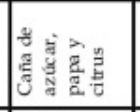 & 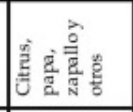 \\
\hline & $=0$ & & 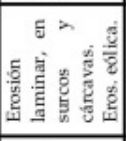 & 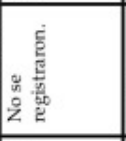 & 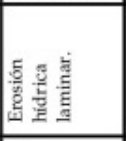 & & & 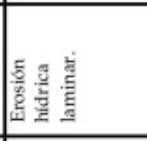 & & 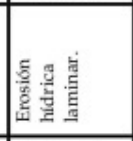 \\
\hline & 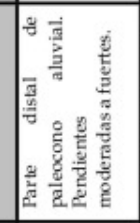 & 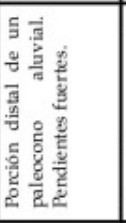 & 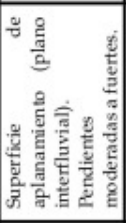 & 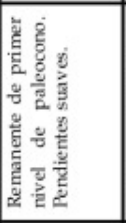 & 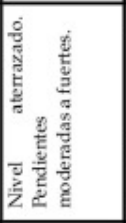 & 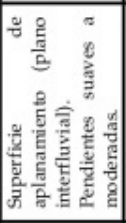 & 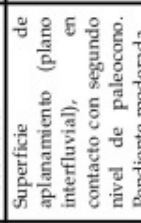 & 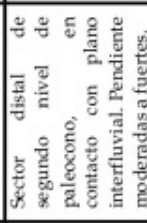 & 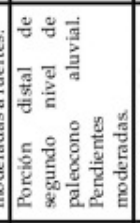 & 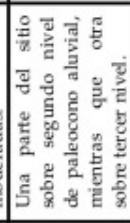 \\
\hline 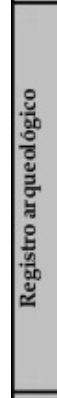 & 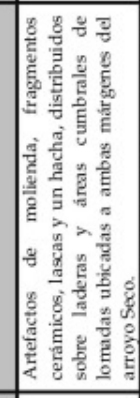 & 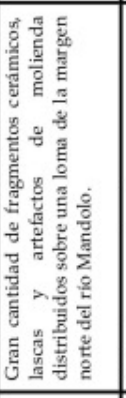 & 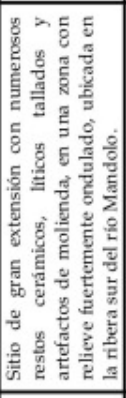 & 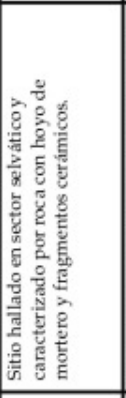 & 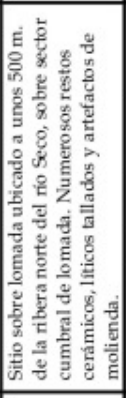 & 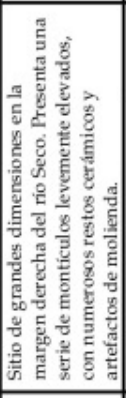 & 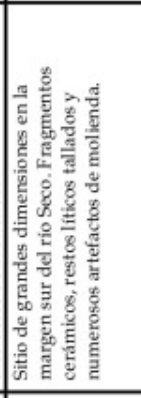 & 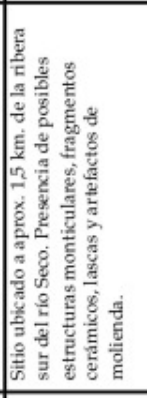 & 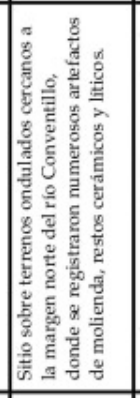 & 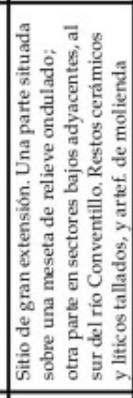 \\
\hline & 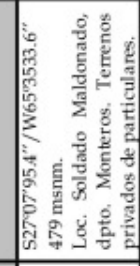 & 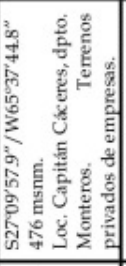 & . & 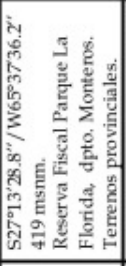 & 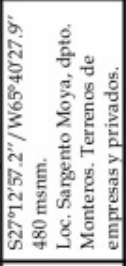 & 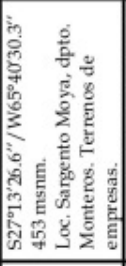 & 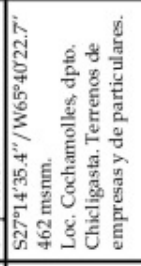 & 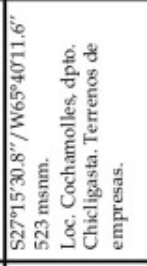 & 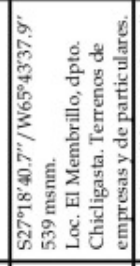 & 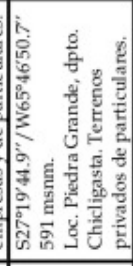 \\
\hline 黄 & 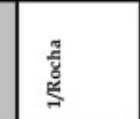 & 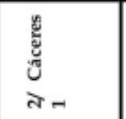 & $\begin{array}{l}\int_{\text {लै }} \\
\text { त }\end{array}$ & $\frac{\pi}{5} \frac{\pi}{5}$ & 的施 & $\begin{array}{r}\frac{8}{4} \\
\frac{5}{2} \\
\frac{5}{2}\end{array}$ & 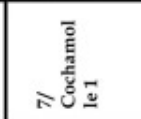 & 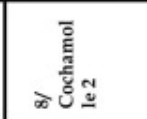 & 泀 & 施泀 \\
\hline
\end{tabular}

Tabla 1. Detalle de los sitios arqueológicos registrados y principales procesos de alteración antrópica que los afectan. 


\begin{tabular}{|c|c|c|c|c|c|c|c|c|}
\hline 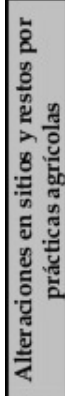 & 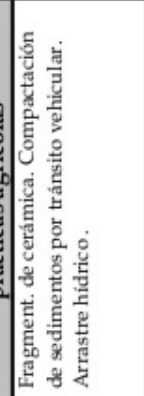 & 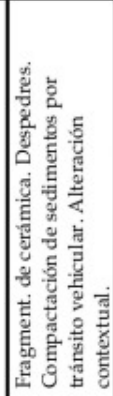 & 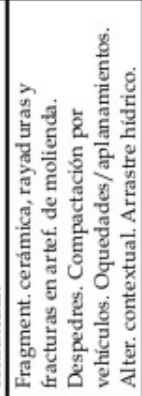 & 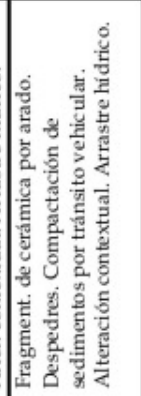 & 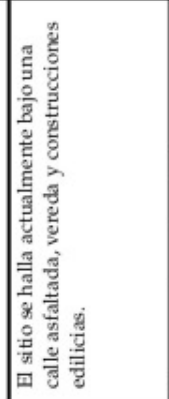 & 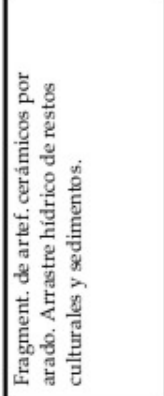 & 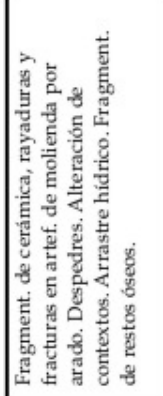 & 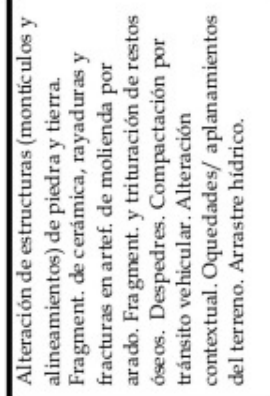 \\
\hline 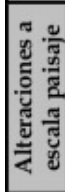 & 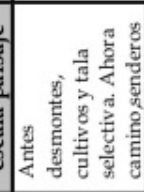 & 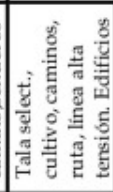 & 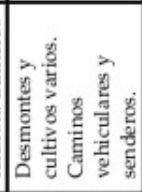 & 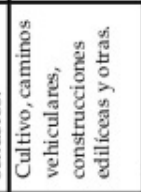 & 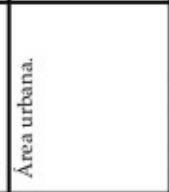 & 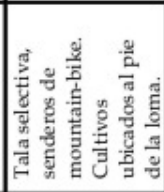 & 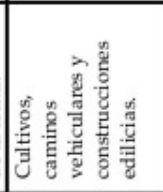 & 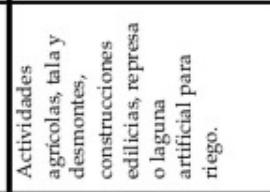 \\
\hline 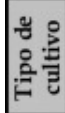 & 造 & E & 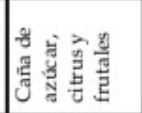 & 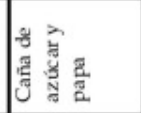 & 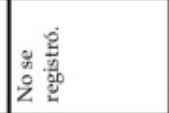 & 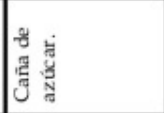 & 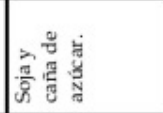 & 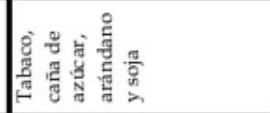 \\
\hline 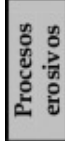 & 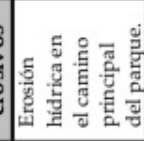 & 列焉 & 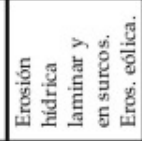 & 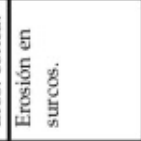 & 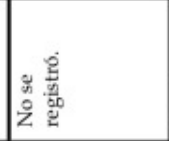 & 总竞 & 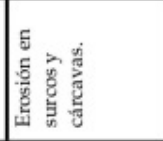 & 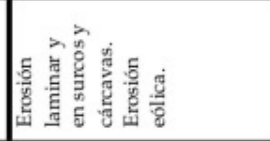 \\
\hline 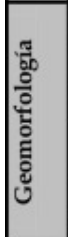 & 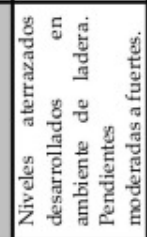 & 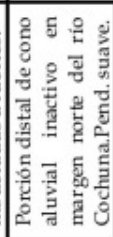 & 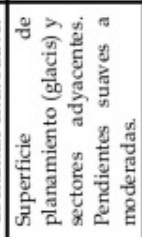 & 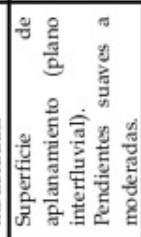 & 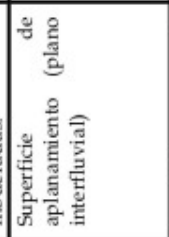 & 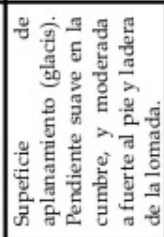 & 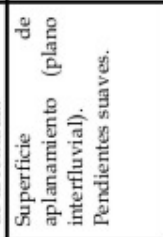 & 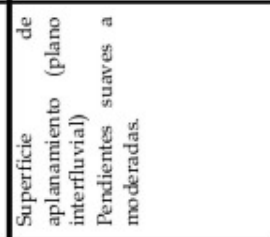 \\
\hline 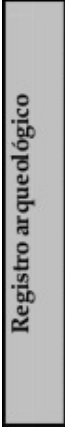 & 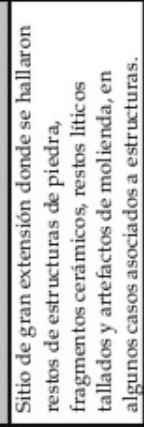 & 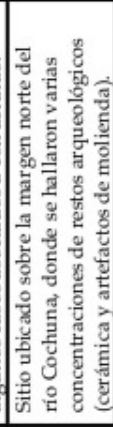 & 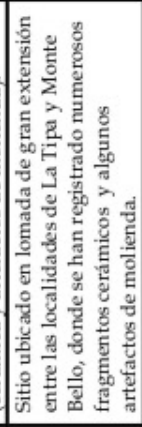 & 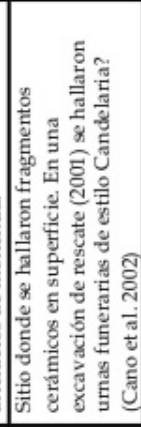 & 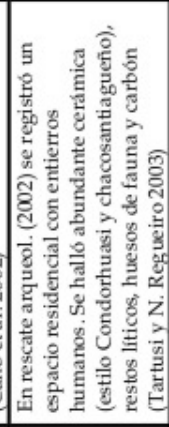 & 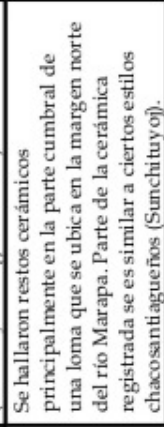 & 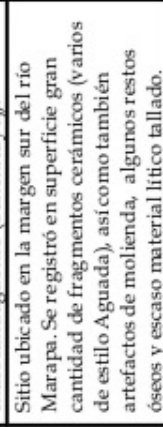 & 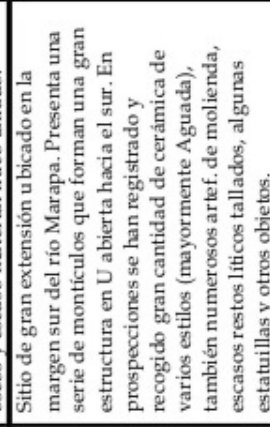 \\
\hline & 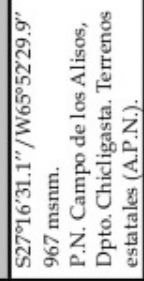 & 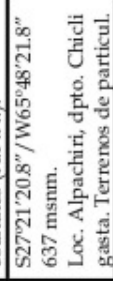 & 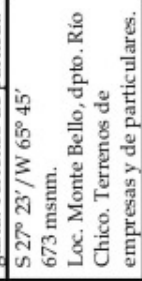 & 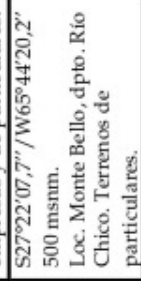 & 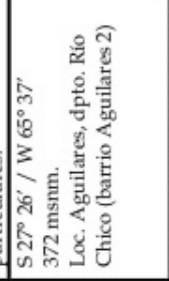 & 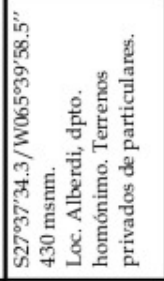 & 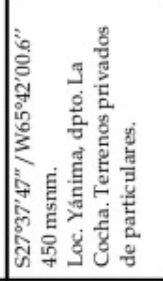 & 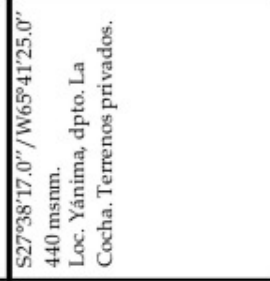 \\
\hline$\frac{9}{3}$ & 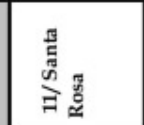 & 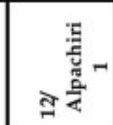 & 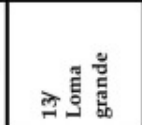 & 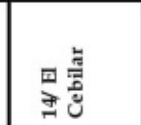 & 的若 & 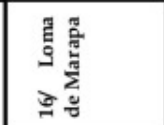 & 牙营 & 尊 \\
\hline
\end{tabular}

Tabla 1 (continuación). Detalle de los sitios arqueológicos registrados y principales procesos de alteración antrópica que los afectan. 
la naturaleza del sustrato, que son fundamentales para comprender los procesos de erosión hídrica. Las diferentes especies cultivadas requieren la aplicación de distintas técnicas para preparar la tierra: la intensidad y profundidad del arado o el tipo de siembra; el abonado con diferentes productos químicos y orgánicos utilizados; la nivelación; el surcado; el sistema de riego, etc. Para tener una idea de las alteraciones que producen estas actividades sobre los recursos arqueológicos analizaremos los casos del cultivo del limón y la caña de azúcar.

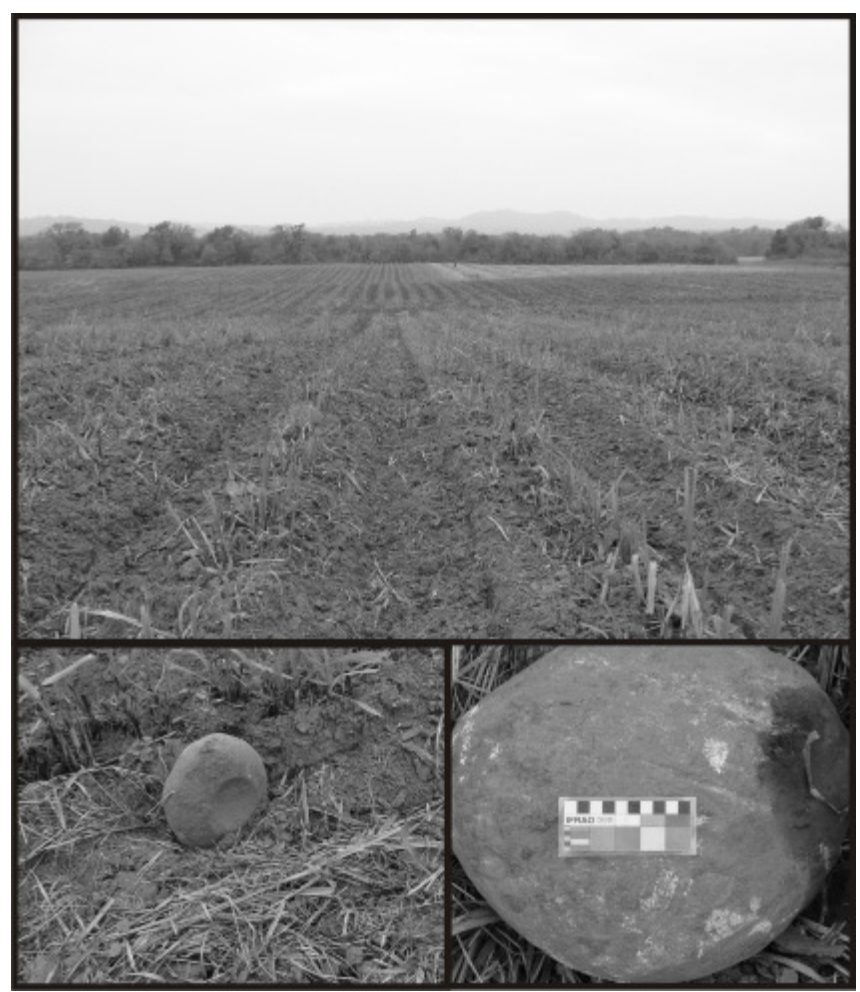

Figura 4. Moyaseco, bajo cultivo de caña de azúcar, y artefacto de molienda con rayaduras de las aspas del arado.

En los sitios Yánimas 1, Cáceres 2, Loma Grande, El Cebilar, Moyaseco (Figura 4), entre otros, se cultiva o cultivaba caña de azúcar en años anteriores. Actualmente se recomienda pasar el subsolador ${ }^{4}$ hasta $l o s$ 50-60 $\mathrm{cm}$ de profundidad para preparar el suelo (para romper capas compactadas de sedimento), y luego dos pasos de arado o rastra pesada hasta los $40 \mathrm{~cm}$ y $30 \mathrm{~cm}$ aproximadamente cada una. Posteriormente se nivela el suelo y se procede a realizar los surcos de siembra de unos 30-35 cm de profundidad (Cabral 2006). Sin duda, este tipo de laboreo produce una fuerte alteración en los restos arqueológicos, sus asociaciones contextuales y estratificaciones. En los restos tales como cerámica y artefactos de molienda de piedra, el paso del tractor y del arado produce fracturas y rayaduras (cicatrices del arado) (Figura 3), mientras que los restos óseos además de fracturarse llegan a triturarse.

Sitios como Cáceres 1 (Figura 5), Cochamolles 1, Cochamolles 2, Loma Grande y La Loma, entre otros, se hallan afectados por plantaciones de limón. Previo marcado del diseño de plantación en el terreno, la siembra del limón se realiza en hoyos de 60 ×60 ×60 cm 
cada 5, 6 o $7 \mathrm{~m}$ de distancia, de acuerdo al diseño elegido. Antes de poner el plantón de limón, se aplica fertilizante orgánico y otros químicos en el fondo de cada hoyo (Castillo Lizano 2004).

El proceso de siembra del limón parece ser menos destructivo para los restos arqueológicos en relación al cultivo de la caña de azúcar, porque el arado de la tierra es menos intenso o no se practica. Sin embargo, centenares de pozos de $60 \mathrm{~cm}$ profundidad dispersos a lo largo de grandes extensiones de un sitio arqueológico dado, sin duda, producen un fuerte impacto sobre los restos y depósitos, alterando sus asociaciones contextuales y estratificaciones.

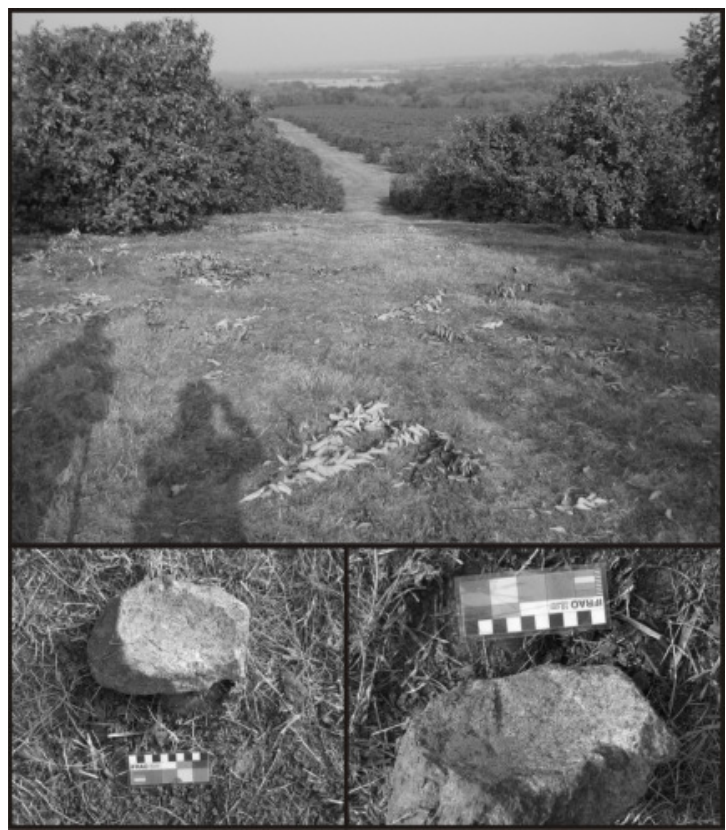

Figura 5. Sitio Cáceres 1, con plantación de limón, y restos arqueológicos alterados.

Alteraciones indirectas: Sistemas de relaciones entre unidades geomorfológicas, tipos de cultivos y sitios arqueológicos.

En cuanto a los sistemas de relaciones "unidad geomorfológica - tipo de cultivo - recurso arqueológico", dos son los más comúnmente observables en el piedemonte meridional tucumano:

a) Paleoconos-citrus-sitio: extensas parcelas de citrus se ubican recurrentemente sobre zonas de lomadas (paleoconos y glacis) o relieves ondulados con alta pendiente. Este factor, sumado a la escasa densidad de cobertura vegetal (unidades por metro ${ }^{2}$ ), favorecen el intenso proceso erosivo durante las lluvias, generando la pérdida de sedimentos y restos arqueológicos, previamente alterados por el desmonte y la siembra. Por ejemplo los sitios Rocha, Cáceres 1 y Cochamolles 2, que se ubican sobre lomadas (paleoconos) con pendientes elevadas, están mayormente afectados por plantaciones de limón. En estos sitios se han observado tanto intensos procesos de erosión laminar como así también surcos y cárcavas que alteran los depósitos del subsuelo y generan el arrastre de un importante volumen de 
sedimentos y restos arqueológicos. Este dato es importante ya que generalmente las cárcavas son rellenadas con sedimentos para evitar el crecimiento de las mismas y horizontalizar nuevamente el terreno.

b) Planos interfluviales-citrus-sitio: los cultivos de caña de azúcar se ubican generalmente en terrenos de menor pendiente, a veces al pie de lomadas. Si sumamos a esta variable el hecho de que este cultivo posee mayor densidad de cobertura vegetal en relación al citrus, podríamos asumir una menor intensidad del arrastre hídrico por erosión de los sedimentos. Sin embargo hay que tener en cuenta que durante los momentos de desmonte, preparación del terreno, siembra y después de la cosecha, el suelo se halla sin vegetación y, por ende, se encuentra propenso a los procesos erosivos hídricos (aunque también eólicos), como se ha observado en varios casos. Sitios como El cebilar, Moyaseco o Cáceres 2, afectados por el cultivo de caña de azúcar, estarían sufriendo procesos erosivos menos intensos (erosión laminar), aunque en algunos casos como en Cáceres 2 la remoción de sedimentos y restos culturales por el agua sería importante debido a las fuertes ondulaciones del terreno

Así como en los ejemplos mencionados, otros sitios arqueológicos registrados situados en diferentes unidades geomorfológicas, están siendo afectados por otros cultivos tales como arándano, soja, tabaco, maíz, papa-semilla, etc., generando distintos tipos e intensidades de alteraciones físico-químicas directas e indirectas en los mismos (ver Tabla 1). Los sitios o sectores de sitios arqueológicos con plantaciones de papa-semilla y soja sufren graves procesos de degradación durante la época de fuertes lluvias, ya que el suelo se halla desprotegido porque estas plantas son de escaso porte y altura, sumado a que algunas veces estos cultivos se desarrollan en zonas de lomadas bajas (por ejemplo, sitio La Escondida, ubicado en la porción distal de un paleocono) u onduladas (como en el sitio Yánimas 2, situado en un plano interfluvial), con elevadas pendientes, generándose gran cantidad de surcos e importantes cárcavas, como la que se registró en Yánimas 2 en el año 2010 (de hasta $2 \mathrm{~m}$ de profundidad por 1,5 a $2 \mathrm{~m}$ de ancho).

Otro de los factores a tener en cuenta en relación a estos procesos que afectan el patrimonio arqueológico pedemontano es el tiempo. La repetición de estas actividades a lo largo del tiempo provocarían el progresivo deterioro de los sitios, generando la gradual desaparición de los mismos, ya que se hallan involucrados en un ciclo destructivo que se repite periódicamente y que consta fundamentalmente de dos pasos: 1- la remociónfragmentación de los sedimentos y materiales arqueológicos y 2- la eliminación por erosión hídrica de sucesivas capas de tierra aradas/cultivadas, agravada por las elevadas pendientes (Miguez 2007).

Cabe preguntarse entonces: ¿cuánto volumen de sedimento con restos arqueológicos se han alterado y perdido producto de estas actividades? Es posible que podamos darnos una idea aproximada en cada caso si llegamos a conocer la "historia agrícola" de los espacios cultivados donde se hallan recursos arqueológicos. Si el tiempo de uso agrícola es largo, e incluso se han producido reemplazos de unos cultivos por otros (por ejemplo, caña de azucar por citrus), entonces comprenderemos que la situación puede ser bastante crítica y difícil de dimensionar. Además, es importante tener en cuenta también que las tecnologías y técnicas agrícolas han cambiado sustancialmente en las últimas décadas. Por ejemplo, la profundidad del arado para cultivar caña era menor en el pasado debido a que se usaban animales de tiro, llegando solo hasta los 20-30 cm. 
La intensidad con que estos procesos afectan a los restos podría mensurarse con mayor detalle en excavaciones arqueológicas a través de variables tales como la distribución horizontal y vertical de los artefactos, el tamaño promedio, forma y grado de abrasión de los fragmentos cerámicos (redondez de los bordes), los índices de fragmentación, entre otros (Schiffer 1987), además de los indicadores que mencionamos en este trabajo.

\section{Aproximación histórica al desarrollo agrícola de la región y su avance sobre los paisajes arqueológicos}

Desde los inicios del período colonial hasta fines del XIX, la explotación agrícola en las tierras bajas de Tucumán estuvo destinada a satisfacer las necesidades de las comunidades que habitaban el territorio provincial, principalmente en base al cultivo de cereales (Natera Rivas y Zamora Batista 2005). Por ende hasta la década del 70 del siglo XIX no existían grandes superficies desmontadas y cultivadas que afectaran en forma significativa los paisajes arqueológicos.

A partir de fines del siglo XIX y principios del siglo siguiente, se registra la primera gran expansión de la frontera agrícola, impulsada por el fuerte desarrollo de los cañaverales e ingenios azucareros y el auge agro-exportador (Campi y Bravo 1999). Así, el cambio de siglo sorprendió a la provincia en pleno proceso de transición desde una agricultura orientada al autoconsumo a otra que destinaba gran parte de su producción a abastecer de azúcar al país. Este cambio se halla reflejado en una considerable extensión de las tierras aradas, alcanzando su máxima expresión en 1960 (Natera Rivas y Zamora Batista 2005). Este período representaría el inicio de la destrucción a gran escala de los paisajes y sitios arqueológicos pedemontanos, con el agravante de que durante este período se incorpora al laboreo de la tierra (y se hace masivo) el uso del arado y de los tractores (da Veiga 2005). Los sectores pedemontanos de los departamentos de Monteros, Chicligasta y Río Chico son los más afectados durante este período.

Luego, después de la crisis agrícola por sobreproducción de caña de azúcar en el año 66 , se produce el auge del citrus, proceso que generó otro gran aumento en las superficies desmontadas y cultivadas desde fines de la década del 60 hasta años recientes. De la mano del limón, los cultivos frutales han ido poco a poco ganando terreno en el piedemonte tucumano (Natera Rivas y Zamora Batista 2005, 2010), reemplazando otros cultivos y generando nuevos espacios agrícolas fundamentalmente hacia el oeste del área, en relieves de lomadas bajas y con fuerte pendiente. Paralelamente, en la última década se ha registrado un importante proceso de diversificación productiva agropecuaria ligado a una creciente demanda internacional, generando nuevas expansiones de la frontera agraria en el piedemonte y llanura aledaña de la mano de la soja, la caña de azúcar y el arándano (Natera Rivas y Batista Zamora 2005; Ministerio de Desarrollo Productivo-Gobierno de Tucumán 2007).

En síntesis, a lo largo de más de 120 años, la expansión de las tierras desmontadas, roturadas y aradas en el piedemonte de Tucumán ha sido tan importante (especialmente en las últimas décadas) que algunos departamentos están afectados por este proceso en casi la totalidad de sus territorios pedemontanos (Natera Rivas y Batista Zamora 2005). Un estudio realizado en la cuenca del río Marapa (dptos. de Alberdi y La Cocha) demuestra que en un período de 30 años, entre 1977 y 2007, 45.456 ha de bosques nativos fueron reemplazados por cultivos (Díaz Gómez 2010). Precisamente, el sector bajo de esta cuenca presenta una gran riqueza arqueológica, con sitios tales como Finca Elías, Loma de Marapa, Yánimas 1, 
Yánimas 2, entre otros, presentando la mayoría de ellos un fuerte impacto producido por las actividades vinculadas al proceso agrícola.

De esta manera, muchos sitios arqueológicos se hallan expuestos a continuos procesos de destrucción por el desarrollo moderno de la agricultura, generándose la inestimable pérdida de una gran cantidad y calidad de información acerca del pasado prehispánico del piedemonte tucumano. Incluso sitios vinculados al período histórico-colonial, también están siendo víctimas de este proceso de degradación. En el sitio "Ibatín" (antiguo asiento de la capital provincial) se ha registrado el avance de parcelas de cultivo (caña de azúcar) sobre amplios sectores de la antigua ciudad (Gramajo Bühler y Di Lullo 2010).

¿Hacia dónde nos dirigimos mientras este proceso continúe? ¿Cuáles son los efectos del desarrollo de la agricultura empresarial sobre el patrimonio arqueológico? Los territorios que sufren de fuertes procesos de agriculturización en sus paisajes tienden a: a- la simplificación y homogeneización del paisaje a causa del aumento de tamaño y cantidad de las parcelas; b- la banalización del paisaje producto de la uniformización de cultivos y prácticas productivas; c- la eliminación de pequeños elementos singulares identitarios (árboles, setos, muros, recursos históricos y arqueológicos, etc.); d- la supresión de de las vías de comunicación ancestrales y caminos rurales por la concentración parcelaria y el alambrado (Ambroise 2002, en Ballesteros Arias et al. 2005).

A estos problemas se suman otros igualmente vinculados a la desaparición progresiva de agricultores y ganaderos tradicionales, así como también de lugares y emociones que vinculaban a los habitantes con el paisaje y lo semantizaban singularizando sus diferentes espacios. Así, el paisaje rural cargado de historias, vivencias y significados diversos deviene en espacio económico, homogéneo, vinculado a individuos y empresas que leen el espacio sólo en términos de productividad. Además, el incremento de la capacidad productiva de las nuevas tecnologías se traduce también en incremento de capacidad destructiva del entorno (Ballesteros Arias et al. 2005). Muchas de estas características son palpables en los parcelados paisajes pedemontanos, debido al proceso de agriculturización que los afectan (Figura 6).

La progresiva expansión y superposición de los paisajes agrícolas históricos sobre los paisajes arqueológicos prehispánicos, se manifiestan en los tipos de alteraciones producidas

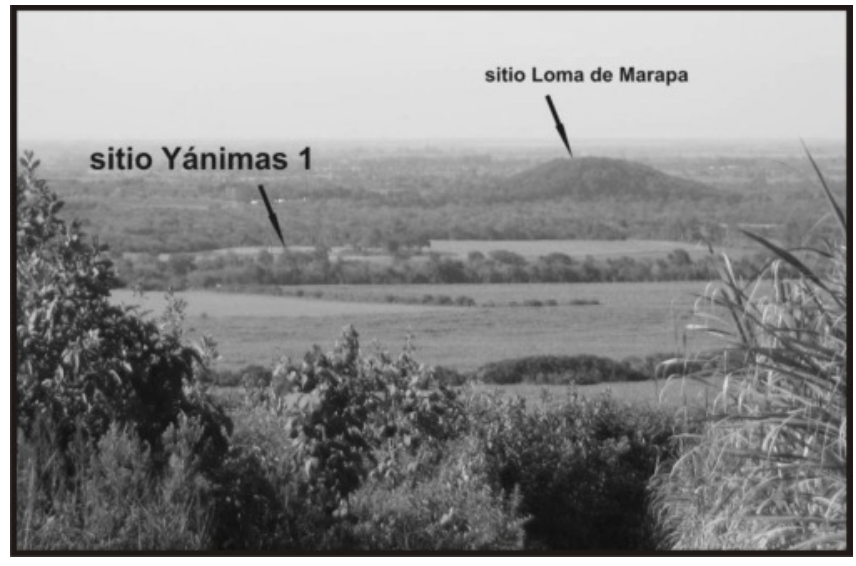

Figura 6. Paisaje arqueológico agriculturizado 
en los restos, sitios y paisajes registrados (Tabla 2). Los sitios se presentan como concentraciones caóticas y descontextualizadas de restos tanto a nivel superficial y subsuperficial (Tabla 1). Pero los sitios considerados en este estudio son solo algunos ejemplos de un proceso que parece estar generalizado y extendido sobre gran parte del área pedemontana de la provincia de Tucumán, y que podría ser considerado como una destrucción a gran escala del patrimonio arqueológico pedemontano, un deterioro masivo y progresivo de paisajes, sitios y objetos prehispánicos producto del desarrollo agrícola moderno.

\begin{tabular}{|l|l|}
\hline Restos & $\begin{array}{l}\text { Rayaduras o cicatrices de arado; fracturas de artefactos cerámicos; líticos } \\
\text { tallados e instrumentos de moler, trituración de restos óseos; alteraciones } \\
\text { de estructuras de tierra o piedra por arado y/o despedres; abrasiones de } \\
\text { objetos por arrastre hídrico. }\end{array}$ \\
\hline Sitios & $\begin{array}{l}\text { Roturación del suelo por diferentes arados; alteraciones verticales y } \\
\text { horizontales de contextos (estratificaciones y distribuciones); producción de } \\
\text { oquedades y aplanamientos del terreno por desmontes y otras actividades; } \\
\text { intensificación de procesos de erosión hídrica localizados o generalizados y } \\
\text { arrastre de restos. Despedres. Pisoteo de animales y personas. Cambios en } \\
\text { el ph del suelo y otras propiedades químicas (por uso de agroquímicos). }\end{array}$ \\
\hline Paisajes & $\begin{array}{l}\text { Alteraciones por construcción de edificaciones, redes viales, construcciones } \\
\text { edilicias, actividades agrícolas, sistemas de riego, represas, desmontes, tala } \\
\text { selectiva, etc. Intensificación de procesos de erosión hídrica a gran escala. }\end{array}$ \\
$\begin{array}{l}\text { Homogeneización, parcelación, destrucción de sitios por sectores o a gran } \\
\text { escala, eliminación de lugares simbólicos }\end{array}$ \\
\hline
\end{tabular}

Tabla 2. Principales alteraciones directas e indirectas producidas por las prácticas agrícolas sobre el patrimonio arqueológico a distintas escalas.

\section{Agricultura vs. Patrimonio arqueológico en el contexto actual sudamericano, nacional y provincial}

Según nuestras observaciones, todas las formas de agricultura (tradicional, empresarial, familiar, etc.) producen, en diferentes formas y magnitudes, alteraciones en los restos arqueológicos. En la provincia de Tucumán todavía puede observarse en la estructura espacial campesina, la coexistencia de múltiples variedades de productores, con sistemas de cultivos que va desde los tradicionales o familiares de huertas con producción para el autoconsumo, hasta complejos y modernos sistemas de explotación agrícola que desarrollan producciones para abastecer las industrias y mercados provinciales, nacionales e internacionales (García y Rofman 2009).

Sin embargo es la agricultura empresarial o moderna ${ }^{5}$ la que, por su carácter expansionista y de vanguardia tecnológica, estaría generando el mayor grado de impacto sobre el patrimonio arqueológico en el área pedemontana (ver Tabla 1). Para la agricultura empresarial, tanto la vegetación nativa como las poblaciones indígenas, rurales o campesinas que albergan sus áreas de explotación son consideradas un estorbo. ¿Por qué? En una realidad económica mundial globalizada y neoliberal, las principales empresas transnacionales agroindustriales son las que ostentan el mayor poder de capital e inciden de forma cada vez más contundente en las economías regionales, considerando a todo el planeta como fuente para sus materias primas, mercado para sus productos y espacio para sus inversiones (Fassi 2009). En este sentido, es sabido que estas empresas proceden sin reparos ni autocrítica a 
desforestar los ecosistemas naturales y a apropiarse de los espacios habitados por dichas comunidades (incluso mediante mecanismos fraudulentos y/o violentos), alterando la identidad territorial de sus habitantes, ante la complicidad o ausencia del Estado (MESA DRS 2007; Curtoni y Chaparro 2008; Fassi 2009).

Esta claro entonces que esta problemática esta generando gravísimas consecuencias ambientales y sociales en la actualidad. Pero hasta el momento se desconoce en qué medida esta situación estaría implicando (o no) un impacto destructivo a gran escala del patrimonio arqueológico en dichas áreas. Según varias fuentes, en provincias tales como Salta, Santiago del Estero, Córdoba, Chaco, entre otras, (así como en otros países de Sudamérica tales como Paraguay, Brasil, Bolivia, etc.), los principales factores de cambio en el uso de la tierra también son la deforestación y la expansión de los espacios agrícolas, fundamentalmente para monocultivo de oleaginosas entre las que se destaca la soja transgénica (Montenegro et al. 2004; Barembaum y Anastasio 2005; MESA DRS 2007; Fassi 2009; García y Rofman 2009; Cabido y Zack 2010). Podríamos sugerir entonces, tomando como ejemplo lo observado en la región abordada en este trabajo, que en otras regiones de Argentina podrían estar sucediendo procesos destructivos del patrimonio arqueológico de similares características.

Además, la expansión del agro sobre las áreas de bosques nativos de nuestro país se suma al hecho de que dichos espacios son poco conocidos desde el punto de vista arqueológico, por lo que se tiene escasa idea tanto del valor patrimonial que albergan como de la magnitud de su destrucción. En Tucumán, por ejemplo, este hecho ha redundado en el escaso o nulo conocimiento que la comunidad tucumana posee sobre el pasado prehispánico de las sociedades que habitaron los espacios pedemontanos, en detrimento de otros períodos de su desarrollo sociocultural (como el histórico-colonial o el de formación del estado provincial o nacional) y de otras área de la provincia (por ejemplo, Valle de Tafí), generando una visión ahistórica de las comunidades originarias que lo habitaron, y causando que su patrimonio carezca de valor cultural e identitario (Miguez 2007).

Se podría alegar entonces una falta de interés en la agenda de los arqueólogos hacia áreas con vegetación densa, probablemente debido a que sus condiciones naturales afectan tanto los restos culturales como el trabajo de campo (intensos procesos de alteración, baja visibilidad, escasa conservación de los restos, elevada temperatura y humedad, etc.). Sin embargo, se considera también que una de las razones fundamentales del escaso conocimiento de la historia prehispánica de las tierras bajas de Tucumán tiene que ver con que las políticas estatales, provinciales e institucionales vinculadas con el impulso y desarrollo de los proyectos de investigación, protección y conservación del patrimonio natural y cultural (en especial el arqueológico) han estado casi siempre subordinadas a programas de desarrollo económico generalmente basados en la explotación descontrolada y poco sustentable de los recursos.

Así, la política económica provincial en Tucumán se ha basado principalmente en el impulso al desarrollo agrícola desde hace más de un siglo, como bandera del progreso económico y social. Esta política se asienta sobre el desconocimiento o, también, la negación del pasado prehispánico y de las poblaciones originarias del piedemonte, cosmovisión que hunde sus raíces históricas en el imaginario colonial (Curtoni y Chaparro 2008).

A partir de esta forma de pensar la realidad, las políticas de protección, investigación, conservación y revalorización del patrimonio arqueológico estarán ausentes o diseñadas 
en base a intereses gubernamentales estatales, provinciales, municipales, etc., mostrándose muchas veces ineficientes y carentes de marcos legislativos e institucionales coherentes. Este tipo de situaciones redundan en la continua destrucción, desaparición y desvalorización patrimonial, como se demuestra aquí.

Si bien existen leyes que reglamentan la protección del patrimonio arqueológico a nivel nacional (por ejemplo, Ley Nacional 25.743) y provincial (Ley Provincial 7.500), estas carecen de efectividad en su aplicación práctica debido a: 1- la falta de control de las instituciones estatales encargadas de aplicar sus disposiciones legales; 2- el poder hegemónico de las empresas agrícolas y los grandes terratenientes que explotan enormes superficies de suelo tucumano para la práctica de monocultivos; 3 - los intereses estatales y de particulares que impulsan la producción agropecuaria a cualquier costo patrimonial, natural o cultural; 4- la insuficiencia de los recursos económicos y humanos para satisfacer las crecientes demandas sociales de intervención, manejo y puesta en valor de dicho patrimonio.

Por ejemplo, la Ley Provincial 7.500 (2005) dispone que toda persona física o jurídica (por ejemplo, empresas) que descubra sitios arqueológicos en sus propiedades o fuera de ellas, deberá denunciarlo ante la autoridad de aplicación de dicha ley (art. 28), o sea a la Dirección de Patrimonio Cultural del Ente Cultural de Tucumán. Sin embargo, los recursos económicos y humanos calificados suelen ser insuficientes para intervenir o actuar en todos los casos denunciados y/o llevar a cabo el registro, monitoreo y control de los sitios arqueológicos amenazados. Como señala Endere $(2001,2002)$, esta situación se hace extensiva a la mayoría de los sistemas legales y administrativos argentinos de protección del patrimonio arqueológico del territorio argentino.

\section{Algunas recomendaciones para el futuro}

En un contexto mundial de economías globalizadas donde las empresas agrícolas explotan y contaminan grandes áreas del planeta, debemos adoptar una participación más activa en defensa del patrimonio arqueológico frente a los intereses político-económicos estatales en razón del avance destructivo del desarrollo agrícola moderno sobre el patrimonio cultural.

Siguiendo esta línea de pensamiento, como primer paso se debe registrar y poner en evidencia (en informes y publicaciones) las graves consecuencias que generan las prácticas agrícolas, demostrando en el espacio-tiempo la magnitud del impacto producido y sugiriendo algunas medidas que tiendan a minimizarlo.

En tal sentido, el registro de los procesos que afectan a los restos arqueológicos es tan importante como las investigaciones tendientes a resolver problemas vinculados con diversos tópicos vinculados a los desarrollos sociales prehispánicos o históricos. En el futuro deberían impulsarse más estudios que impliquen el relevamiento y estado de conservación de los sitios arqueológicos, en el marco de proyectos o programas de investigación financiados por el estado nacional y los estados provinciales, principalmente en aquellas áreas tan afectadas como la que se describe en este trabajo.

Por otra parte, para que las disposiciones legales tengan mayor eficacia y aplicabilidad en casos concretos, deberían crearse unidades especiales constituidas con agentes de protección del patrimonio arqueológico que monitoreen los sitios arqueológicos amenazados y tengan la facultad de aplicar sanciones y multas a quién corresponda por acciones ilegales que afec- 
tasen dicho patrimonio. Estas unidades se podrían crear a través de convenios entre las instituciones policiales y culturales encargadas del manejo de los recursos culturales. A través de estos convenios se podrían implementar programas de formación de agentes de protección del patrimonio cultural arqueológico e histórico por parte de profesionales idóneos en la materia.

Además, el estado provincial debería impulsar programas de difusión y capacitación a distintos agentes sociales (en este caso a los representantes de las empresas agrícolas y agricultores en general) con el objeto de mostrarles el impacto que producen sus actividades, recomendarles medidas que tiendan a atenuarlo y transferirles la importancia de preservar este patrimonio para su investigación, difusión y construcción de una identidad social con el pasado.

\section{Agradecimientos}

Las tareas de investigación que sustentaron la realización de este trabajo fueron financiadas por CONICET y por el Consejo de Investigaciones de la Universidad Nacional de Tucumán (CIUNT). Mi más sincero agradecimiento a todos aquellos colegas y estudiantes que me acompañaron en las travesías pedemontanas. Agradezco también al Dr. Mario Caria por sus útiles comentarios, así como también a las sugerencias de los evaluadores anónimos que permitieron mejorar la versión final de este artículo. Todo lo vertido aquí es de mi entera responsabilidad.

\section{Notas}

${ }^{1}$ La mayoría de los sitios trabajados (descriptos en la Tabla 1) han sido descubiertos en las prospecciones efectuadas por el autor, mientras que otros ya habían sido registrados por otros investigadores, como es el caso de El Cebilar (Cano et al. 2002), Aguila 2 (Tartusi y Núñez Regueiro 2003), y Loma de Marapa y Yánimas 1 (Manasse 1997). Además existen otros sitios en el área relevados por Korstanje (1991) para la zona de Monte Bello, y por Tartusi y Núñez Regueiro (2003) para la cuenca baja del río Marapa, en los que todavía no se han llevado a cabo relevamientos en el marco de este estudio.

${ }^{2}$ El concepto de sitio ha sido muy discutido en la literatura arqueológica. Comúnmente se lo ha definido como concentración o agrupación definida de restos arqueológicos (Plog et. al. 1978; García Sanjuán 2005; entre otros). Sin embargo, acuerdo con Chapa Brunet y colaboradores (2003) que las concentraciones dejan de lado los materiales que se hallan fuera de ellas. Además varias concentraciones pueden formar parte de un solo sitio de ocupación, como suele suceder en un área de tanta dinámica ambiental como la considerada en este trabajo. Para sortear esta dificultad elegimos el término distribución, porque considero que los sitios están formados distribuciones (regulares e irregulares, continuas o discontinuas) de materiales, las cuales son conceptualmente más abarcativas, y pueden incluir a las concentraciones, los no-sitios y hallazgos aislados.

${ }^{3}$ Los sitios Yánimas 1, Yánimas 2 y Loma de Marapa no están incluidos en el mapa geoarqueológico porque, como ya se ha señalado, no se pudieron acopiar todas las fotografías aéreas correspondientes a la zona donde se ubican los mismos (al sur del área del mapa) y necesarias para el correcto relevamiento geomorfológico y su posterior digitalización en un mapa completo. Sin embargo, hemos decidido incluirlos en la Tabla 1 porque se hallan dentro del área estudiada por el autor mediante un proyecto doctoral (Miguez 2008). Para un mayor detalle acerca de la descripción de las unidades geomorfológicas definidas para el área, remitimos al lector al trabajo Miguez y Collantes (2012).

${ }^{4} \mathrm{El}$ subsolador es un arado usado para roturar el suelo a mayor profundidad $(50 \mathrm{~cm}$. o más) y así romper las capas compactadas naturales o producidas por labores agrícolas, y mejorar su fertilidad. Su uso en recomendado para varios tipos de cultivos (caña de azúcar, arándano, limón, soja, etc.) (Sanhueza 2002). ${ }^{5}$ La Agricultura Empresarial, integrada a las demandas del mercado regional e internacional, se especializa en la producción de monocultivos en superficies extensas, maximizando los ingresos mediante la utilización intensiva de tecnologías modernas y de agroquímicos. Por el contrario, la Agricultura Tradicional, se basa en el íntimo conocimiento del medio biótico y la prolongada experiencia histórica en el manejo de los cultivos, transmitida a lo largo de generaciones. La producción es de carácter subsistencial (familiar), en superficies poco extensas y con bajo nivel tecnológico (Ramirez 2007). 


\section{Bibliografía Citada}

Amado Reino, X., Barreiro Martínez, D., Criado Boado, F., y M. Martínez López

2002 Especificaciones para una Gestión Integral del Impacto Arqueológico desde la Arqueología del Paisaje. TAPA 26: 12-161.

Ballesteros Arias, P., Otero Vilariño, C. y R. Varela Pousa

2005 Los Paisajes Culturales desde la arqueología: propuestas para su evaluación, caracterización y puesta en valor. ArqueoWeb 7(2), versión digital: http://www.ucm.es/info/arqueoweb.

Barembaum, M. y M. Anastasio

2005 Caracterización económica de la provincia de Santiago del Estero: evolución de la agricultura en la provincia. Apuntes Agroeconómicos 3: 21-28.

Brown, A., Grau, H., Malizia, L. y A. Grau

2001 Los bosques nublados de la Argentina. Bosques nublados del neotrópico (ed. por M. Kapelle y A. Brown), pp. 623-659. INBio, Costa Rica.

Brown, A. y L. Malizia

2004 Las Selvas Pedemontanas de Las Yungas: En el umbral de la extinción. Ciencia Hoy 14 (83): 52-63.

Cabido, M. y M. Zack

2010 Deforestación, agricultura y biodiversidad. Hoy la Universidad, versión digital: http:/ /www. hoylauniversidad.unc.edu.ar/2010/junio/deforestacion-agricultura-y-biodiversidad-apuntes.

Cabral, D.

2006 Preparación de suelo para cultivo de caña de azúcar. Suplemento Rural ABC, versión digital: http://iabc.com.py/suplementos/rural/articulos

Cano, S., Zurita, R., Argañaraz Fochi, D., Romano, A., Rendace, S., Rodríguez, R., Sánchez, S., López, F., Gallardo, P., Retes, M. y L. Di Vece.

2002 Rescate arqueológico de urnas funerarias en la localidad de Monte Bello, Provincia de Tucumán (sitio STUCrch 1, Monte Bello - El Cebilar). Actas de Resúmenes del VII Congreso Nac. de Estudiantes de Arqueología, pp. 13. San Pedro de Colalao, Tucumán.

Campi, D. y M. C. Bravo

1999 La agro-industria azucarera argentina. Resumen historiográfico y fuentes. America Latina en la Historia Económica 11: 73-93.

Castillo Lizano, J.

2004 Manual técnico de Citrus. Asociación Tucumana del Citrus, versión digital: http:/ /www. atcitrus.com/manual_citrus.htm

Chapa Brunet, T., Uriarte Gonzalez, A., Vicent García, J. M., Mayoral Herrera, V. y J. Pereirasieso 2003 Propuesta metodológica para una prospección arqueológica sistemática: el caso del Guadiana Menor (Jaén, España). Trabajos de Prehistoria 60 (1): 11-34.

Criado Boado, F.

1991 Construcción social del espacio y reconstrucción arqueológica del paisaje. Boletín de Antropología Americana 24: 5-29.

1993 Límites y posibilidades de la Arqueología del Paisaje. SPAL 2: 9-55. 
1996 La Arqueología del Paisaje como Programa de Gestión Integral del Patrimonio Arqueológico. Boletín del Instituto Andaluz del Patrimonio Histórico 14:15-19.

1999 Del terreno al espacio: Planteamientos y perspectivas para Arqueología del Paisaje. CAPA 6: 1-77.

Curtoni, R. y G. Chaparro.

2008. El espejo de la naturaleza y la enfermedad histórica en la construcción del conocimiento. Intersecciones en Antropología 9: 213-227.

da Veiga, A.

2005 La soja y la expansión de la frontera agrícola argentina. Soja - Eficiencia de Cosecha y Postcosecha, INTA-PRECOP, Manual técnico $N^{\circ} 3$ (ed. por M. Bragachini y C. Casini), pp. 9-20. INTA, Buenos Aires.

Díaz Gómez, A.

2010 Cambios de la cobertura del territorio en la cuenca del río Marapa, entre 1977 y 2007, Tucumán. Tesina de grado. Universidad Nacional de Tucumán, San Miguel de Tucumán.

Endere, M. L.

2000 Arqueología y legislación en Argentina. Cómo proteger el patrimonio arqueológico. Serie Monográfica 1. INCUAPA, Olavarría.

2001. Patrimonio arqueológico en Argentina. Panorama actual y perspectivas futuras. Revista de Arqueología Americana 20: 143-158.

2002. Arqueología, política y globalización. ¿Quién se ocupa del patrimonio arqueológico? Cuadernos UNJu 18: 69-76.

Fassi, M.

2009 Agricultura empresarial y globalizaciones. Los efectos de la soja transgénica en el Paraguay. Revista Herramienta 40 (13), versión digital: http:/ / www.herramienta.com.ar/revista-herramienta

García, A. y A. Rofman.

2009 Agrobusiness y fragmentación en el agro argentino: desde la marginación hacia una propuesta alternativa. Mundo Agrario 19 (10), versión digital: http:/ / www.mundoagrario. unlp.edu.ar/numeros/no-19-2do-sem-2009

Garcia Azcarate J. y M. Korstanje

1995 La ocupación prehispánica de las selvas de montaña tucumanas. Investigación, Conservación y Desarrollo en Selvas Subtropicales de Montaña (ed. por A. Brown y H. Grau), pp. 175-182. LIEY, Tucumán.

García Sanjuán, L.

2005 Introducción al Reconocimiento y Análisis Arqueológico del Territorio. Ed. Ariel, Barcelona.

Gramajo Bühler, M. y E. Di Lullo.

2010 La Arqueología en los Estudios de Impacto: Primera línea de base arqueológica del sitio histórico de Ibatín. IV Jornadas de Jóvenes Investigadores UNT-CONICET, versión digital: http://www.ct.unt.edu.ar/pubjornadas2010/trabajos/35.pdf 
Hernando, A.

2004 Arqueología de la identidad. Una alternativa estructuralista para la arqueología cognitiva. Teoría arqueológica en América del Sur (ed. por G. Politis y R. Peretti), pp. 33-56. INCUAPA, Olavarría. Korstanje, M. A.

1991 Estudio del Formativo Inferior en el Sud de la Provincia de Tucumán. Informe Final. Beca Pre-iniciación CONICET, Tucumán.

1992. Avances en el conocimiento del Formativo en el piedemonte oriental del Aconquija (SO de Tucumán). Cuadernos UNJu 4: 175-181.

Legislatura de la Provincia de Tucumán.

2005 Sistema de Protección del Patrimonio Cultural y de los Bienes Arquitectónicos. Leyes 7.500 y 7535. Dirección de Taquígrafos de la H. Legislatura de la Provincia de Tucumán, Tucumán.

Manasse, B.

1997 La región pedemontana del Sudoeste de la Provincia de Tucumán. Departamentos de Alberdi y La Cocha. Shincal 6: 141-152.

Mancilla, M., Ledesma, M. y F. Zampella

2010 Documento Informativo de la Provincia de Tucumán. Proyecto IDE Tucumán, Dirección de Estadística, Secretaría de Planeamiento, Gobierno de Tucumán, San Miguel de Tucumán.

Mesa de Concertación para el Desarrollo Rural Sostenible [MESA DRS].

2007 Uso indiscriminado de agrotóxicos en Paraguay, versión digital: http:/ / www2.ohchr.org/ english/bodies/cescr/docs/info-ngos/descmesadrs1_sp.doc.

Miguez, G.

2007 ¡Alerta! Más vale tarde que nunca...La gran destrucción del patrimonio arqueológico en el piedemonte tucumano. Serie Monográfica y Didáctica 46: 41.

2008. Paisajes arqueológicos y dinámica de ocupación prehispánica en el piedemonte meridional tucumano. Proyecto de Tesis Doctoral. Universidad Nacional de Tucumán, Tucumán. 2011 Paisajes arqueológicos y dinámica de ocupación prehispánica en el piedemonte meridional tucumano. Informe de avance de tesis doctoral. Universidad Nacional de Tucumán, Tucumán.

Miguez, G. y M. Collantes

2012 Geoarqueología de un sector del área pedemontana meridional de la provincia de Tucumán. Actas del V Congreso de Geomorfología y Geología del Cuaternario (en prensa). Río Cuarto, Córdoba.

Ministerio de Desarrollo Productivo.

200. Informe 2003-2007. Gobierno de la Provincia de Tucumán, versión digital: http://www. producciontucuman.gov.ar/publicaciones/ informe.pdf.

Molinari, R., Ferraro, L., Paradela, H., Castaño, A. y S. Caracotche

20002001 Odisea del Manejo: Conservación del Patrimonio Arqueológico y Perspectiva Holística. II Congreso Virtual de Antropología y Arqueología, NAYA, versión digital: http:/ / www.naya.org.ar/congreso2000/ponencias/Roberto_Molinari2.htm

Montenegro, C., Gasparri, I., Manghi, E., Strada, M., Bono, J., y M. G. Parmuchi. 2004 Informe sobre deforestación en Argentina. Dirección de Bosques, Secretaría de Ambiente y Desarrollo Sustentable. Ministerio de Salud y Ambiente, Argentina. 
Natera Rivas, J. y A. Zamora Batista 2005 La Evolución del Sector Agrícola en Tucumán (Argentina) desde finales del XIX: Una aproximación a través de la dinámica de los grupos de cultivos. Scripta Nova 9 (197), versión digital: http://www.ub.es/geocrit/sn/sn-197.htm

2010 El complejo agroindustrial limonero de la provincia de Tucumán (Argentina): Ejemplo de producciones no tradicionales y de desaparición de los pequeños productores. Boletín de la Asociación de Geógrafos Españoles 53:67-88.

Prats, L. 1997 Antropología y patrimonio. Ariel, Barcelona.

Plog, S., Plog, F., y W. Wait

1978 Decision making y modern surveys. Advances in Archaeological Method and Theory 1 (ed. por M. Shiffer), pp. 384-421. Academic Press, New York.

Ramirez, A.

2007 Proceso de análisis jerárquico con base en funciones de producción para planear la siembre de maíz de temporal. Tesis Doctoral. Colegio de PostGraduados de Texcoco, México.

Sanhueza, J.

2002 Prácticas de adecuación de suelo. Arado subsolador y cincel. Serie Actas 20: 92-107.

Sayago, J.

1982 Las unidades geomorfológicas como base para la evaluación integrada del paisaje natural. Acta Geológica Lilloana 16 (1): 170-180.

Sayago, J., Collantes, M. y M. Toledo.

1998 Geomorfología. Geología de Tucumán (ed. por M. Gianfrancisco, M. Puchulu, J. Durango de Cabrera y G. Aceñolaza), pp. 241-258. Colegio de Graduados en Cs. Geológicas, Tucumán.

Scattolin, M.C. y M. A. Korstanje

1994 Tránsito y frontera en los Nevados del Aconquija. Arqueología 4: 165-197

Sesma, P., Guido, E. y M. Puchulu

1998 Clima de la Provincia de Tucumán. Geología de Tucumán (ed. por M. Gianfrancisco, M. Puchulu, J. Durango de Cabrera y G. Aceñolaza), pp. 41-46. Colegio de Graduados en Cs. Geológicas, Tucumán.

Shiffer, M.

1987 Formation Processes of de Archaeological Record. University of Utah Press, Salt Lake City.

Tartusi, M. y V. Núñez Regueiro

2003. Procesos de interacción entre poblaciones de los valles intermontanos del noroeste argentino y las del piedemonte. Anales Nueva Época 6 (ed. por P. Cornell y P. Stenborg), pp. 44-60. Instituto Iberoamericano, Univ.de Goteborg, Suecia.

\section{UNESCO}

1972. Convención sobre la protección del patrimonio mundial, cultural y natural. Versión digital: whc.unesco.org/archive/convention-es.pdf, París. 